\section{Succession Planning}

As succession stories go, this one could be titled "The Good, The Bad, and the possibly-but-hopefully-not Ugly." A physician, just promoted to the top job in his group, received the piece of congratulatory good news - that big promotion-along with a bonus of bad news.

His boss and longtime mentor, the very doctor he would replace and a man who had strongly supported his ascension, had decided to stick around after all—as a new board member, presumably providing oversight.

"Will he be in my way? Will the board turn to him, instead of me?" asked the soon-to-be physician leader in a letter to management columnist Howard Kirz MD, MBA, past president of the American College of Physician Executives. "Sit down with your mentor," Kirz advised. Try to find a solution, he urged, maybe by suggesting an emeritus role for the mentor, or perhaps a consulting position, in lieu of taking that board post. ${ }^{1}$

In fact, commitment to solving these thorny issues as they arise can nip them in the bud, preventing them from growing into a virtual thicket, say some oncologists. At its best, succession focuses on identifying and grooming potential leaders to step into the executive office, while, conversely, allowing a graceful exit for the incumbent, who, when willing to do so, can assist in a successful transition. ${ }^{2}$

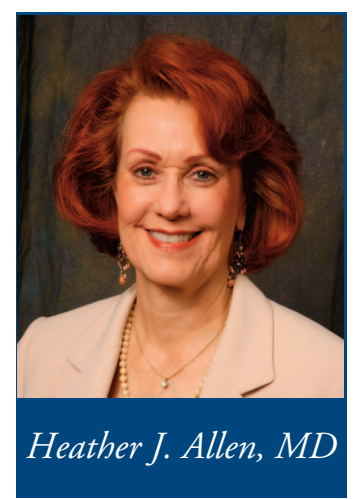

Heather J. Allen, MD, of Las Vegas, NV, a physician who has been in practice more than 25 years, notes that succession planning works best as a continual, visible process. In a practice with multiple physicians such as hers, it is important for that process to be above board. She says, in fact, it needs to be recognized as just another way of working toward long-range practice goals.

Allen stresses that it is essential to discuss retirement issues among colleagues. "Most people have a general idea of when they want to retire," she notes. However, it can be critical to talk about a "life plan," so that there is a more seamless progression to termination of practice. She likened it to a pipeline, adding that, without this steady flow, problems may surface: aging physicians cannot wait to leave because of the ongoing high demands of practice, but may soon regret it; doctors continue to work at a break-neck pace because there is no alternative other than the one they've been doing all those years. She has seen colleagues who knew precisely when they wanted to leave, but with many others, the departure was more gradual—a tapering off during a period of several years.

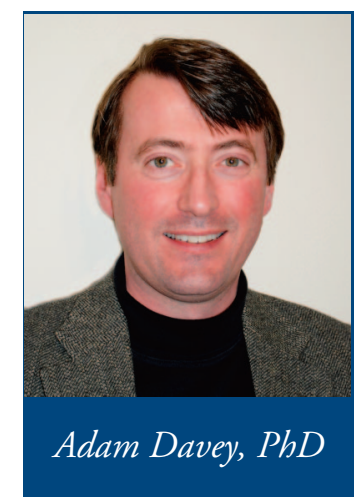

The latter approach can both extend work life and make the transition out of it easier when that time comes. In careers such as medicine, where the job has high intrinsic meaning and value to the individual, "letting go around retirement can be difficult," says Adam Davey, PhD, a developmental psychologist at the College of Health Professions at Temple University, Philadelphia, PA. "After spending so much of your career trying to build a successful practice, you want to ensure that it will continue to thrive and that your legacy can continue successfully."

In Allen's practice group, Comprehensive Cancer Centers of Nevada, Las Vegas, NV, physicians age 55 years and older no longer have to take weekday call; those 60 years and older no longer have to take weekend call; and those 65 years and older don't have to do hospital consults.

This approach works well for Allen's practice and the current professional climate seems likely to mean that approach will work well in the future, too, and for a very basic reason: a looming physician shortage. The American Society of Clinical Oncology projects a significant dearth of medical and gynecologic oncologists by $2020,{ }^{3}$ findings that have been bolstered from tracking by the American Association of Medical Colleges ${ }^{4}$ and by data published in recent journal studies. ${ }^{5}$

Why is this occurring? If government statistics are as representative of the medical community as they are of other white-collar professionals, the fast track is losing its appeal to a large cohort of people known for their quality-of-life quest- the baby boomers. If present demographic trends prove true in years to come, this boom generation will retire much sooner than their parents did, even though they are likely to live longer and in better health. National figures show voluntary retirement ages are ticking downward, even as longevity is increasing, making work life theoretically much easier to extend. ${ }^{6}$

Accounts of physicians leaving practice to drive a cab or manage a restaurant have made headlines in professional publications. ${ }^{7,8}$ But a likelier scenario comes from a recent online advertisement for an oncologist that simply informs job seekers that retirement beckons and a replacement is needed-and an eager and stable staff awaits a new physician.

One of the ways to build a sustainable practice, according to Denis Hammond, MD, of New Hampshire OncologyHematology PA in Hooksett, NH, is to reduce the time 


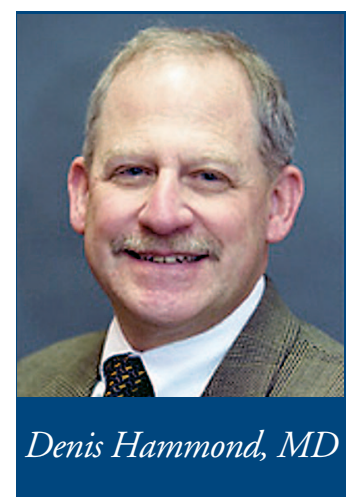

physicians spend within it. At a time when business experts are warning about the negative toll of the 70-hour extreme work week, the oncologists' full-time schedules seem in prescient contrast. He and his partners, in general, work a 4.5 day week: 4 days in clinic, and a half day devoted to administrative tasks. In addition, all of them get 6 weeks of personal time, and a monthlong sabbatical about every 9 years. (The days are 12 hours long generally, so the work week is about 54 hours.)

That's still a long week, but it falls short of the 60 or more hours per week that the Center for Work-Life Policy in New York City, NY, warns has become the norm for some in fields of highly educated professionals. One risk of such a model is that it threatens to "cull talent" that otherwise "could have reached the top," according to investigators. ${ }^{9}$

So is a 54-hour work week simply a savvy way to raise morale? $\mathrm{Or}$ is it a good strategy to keep attracting new talent? Likely both, but the benefit Hammond has seen is in long-term productivity. "If you cut back on volume, it extends the time you can work," he says, citing himself as an example. He cut back his own schedule a few years ago. Despite three decades of practice, "I feel energized again," Hammond adds, crediting the reduction in hours.

Succession planning got its start in Hammond's practice with the departure of the practice's founding physician 13 years ago. The partners began searching for ways to make future transitions go smoothly. Eventually an executive committee was formed, with a perpetual goal to keep paving the way for developmental growth. Hammond says the culture of the place seems to support developmental growth. There is topdown transparency, he says - and when he leaves, "I don't think there will be a sacred text I need to unveil."

When Jim Collins, author of the bestseller Good to Great, looked at how companies make the leap to greatness, he found some characteristics consistent with those that

\section{References}

1. Kirz H: Ask the Coach. The Physician Executive 30(3): 67-68, 2004

2. Leadership succession and transition practice: Talent management in health care and higher education. http://wittkieffer.com/cmfiles/reports/Succession_ Planning_r5.pdf

3. Erikson C, Salsberg E, Forte G, et al: Future supply and demand for oncologists: Challenges to assuring access to oncology services. J Oncol Pract 3:79-86, 2007

4. Fuchs E: AAMC holds workforce research conference. AAMC Reporter Vol 16, 2007

5. Cooper RA, Getzen TE, McKee HJ, et al: Economic and demographic trends signal an impending physician shortage. Health Affairs 21:140-154, 2002

6. US Office of Personnel Management: Retirement highlights overview. https: www.opm.gov/feddata/retire/rs2004_highlights.pdf

7. Snyder J: Ariz. ERs face patient crunch, staff shortages. http://www. azcentral.com/arizonarepublic/news/articles/0814biz-erdoc0814-intro.html

8. Bates B: Surgeons Decry Low Fees, High ED Expectations. Surgery News 3:1, 4, 2007
Hammond cites. Successors are set up to flourish through the cultivation and cooperation of the current leadership, and the leaders responsible for ensuring that have one common trait: humility-humbleness that would make a "sacred text," to use Hammond's phrase, an oxymoron.

Hammond also advocates a strong, persistent personal touch with colleagues. "One of my mantras is that people need to be mentored or instructed," he says. On the other hand, the learning curve goes both ways. Fresh ideas come from all quarters of the business. "The more you plan, the more likely you are to avoid problems," he stresses.

Problem avoidance is important because, in addition to avoiding the pitfalls of practice disruption, there seems to be a critical association, perhaps even a direct relationship, between work-related stress and a greater likelihood of patient errors. ${ }^{10}$ In fact, a nationwide physician survey shows that a good feeling about the workplace, often resulting from camaraderie with colleagues and a sense of helping the team meet high standards, is a prime determinant of physician well-being in practice. ${ }^{11}$

Or, as Daniel Klass, MD, of Toronto, Ontario, Canada, put it, in an editorial in the New England Journal of Medicine, the era of the "lone ranger" is over. ${ }^{12}$ "Given the actual nature of doctors' work, it is clear that what is often considered individual competence depends critically on multiple working relationships - including the primary ones with patients, but also those with coworkers, colleagues, consultants, and others," he states.

In an essay on professionalism, surgeon Rosa E. Cuenca, MD, sounded a similar note. ${ }^{13}$ Summing up for a coming generation of physicians what it means to be a doctor amid today's stress-inducing pace, she asserts. "Being a physician is not glamorous; it is a service-a lifelong endeavor." It is something that "comes naturally to some, is perfected with time, and stays with us, I hope, long after we take down our shingle."

DOI: 10.1200/JOP.0832506

9. Hewlett S, Buck Luce C: Extreme jobs: The dangerous allure of the 70-hour workweek. http://harvardbusinessonline.hbsp.harvard.edu/b02/en/common/ item_detail.jhtml?id=R0612B\&referral $=2342$

10. Williams ES, Baier Manwell L, Konrad TR, et al: The relationship of organizational culture, stress, satisfaction, and burnout with physician-reported error and suboptimal patient care: Results from the MEMO study. Health Care Manage Rev 32:203-212, 2007

11. Douglas J, Gerrity M, Konrad TR, et al: Physician, practice, and patient characteristics related to primary care physician physical and mental health: Results from the physician worklife study. Health Services Research 35:333-349, 2002

12. Klass D: Assessing doctors at work - progress and challenges. N Engl J Med 356:414-415, 2007

13. Ceunca RE: Professionalism, in Lo Chin E (ed): This Side of Doctoring: Reflections From Women in Medicine. Thousand Oaks, CA, Sage Publications 2002, p 229 